\title{
Phytopathology
}

\section{Quantitative Trait Loci Conferring Leaf Rust Resistance in Hexaploid Wheat}

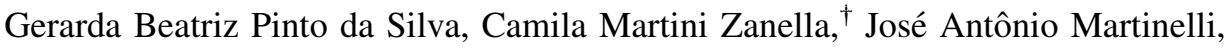 \\ Márcia Soares Chaves, Colin W. Hiebert, Brent D. McCallum, and Lesley Ann Boyd
}

First and third author: Universidade Federal do Rio Grande do Sul (UFRGS), Av. Bento Gonçalves, 7712. Porto Alegre, RS, Brazil; second and seventh authors: NIAB, Huntingdon Road, Cambridge, CB3 OLE, UK; fourth author: Empresa Brasileira de Pesquisa Agropecuária-Embrapa Clima Temperado, Rodovia BR-392, Km 78, Pelotas, RS, Brazil; and fifth and sixth authors: Cereal Research Centre, Agriculture and AgriFood Canada, 101 Route 100, Morden, MB R6M 1Y5, Canada.

Accepted for publication 6 September 2018.

\begin{abstract}
Leaf rust, caused by the fungal pathogen Puccinia triticina, is a major threat to wheat production in many wheat-growing regions of the world. The introduction of leaf rust resistance genes into elite wheat germplasm is the preferred method of disease control, being environmentally friendly and crucial to sustained wheat production. Consequently, there is considerable value in identifying and characterizing new sources of leaf rust resistance. While many major, qualitative leaf rust resistance genes have been identified in wheat, a growing number of valuable sources of quantitative resistance have been reported. Here we review the progress made in the genetic identification of quantitative trait loci (QTL) for leaf rust resistance detected primarily in field analyses, i.e., adult plant resistance. Over the past 50 years, leaf rust resistance loci have been assigned to genomic locations through chromosome analyses and genetic mapping in biparental mapping populations, studies that represent 79 different wheat leaf rust resistance donor lines. In addition, seven association mapping studies have identified adult plant and seedling leaf rust resistance marker trait associations in over 4,000 wheat genotypes. Adult plant leaf rust resistance QTL have been found on all 21 chromosomes of hexaploid wheat, with the B genome carrying the greatest number of QTL. The group 2 chromosomes are also particularly rich in leaf rust resistance QTL. The A genome has the lowest number of QTL for leaf rust resistance.
\end{abstract}

\section{THE HOST-RUST SYSTEM}

Hexaploid wheat (Triticum aestivum L.; AABBDD) is believed to have originated some 10,000 years ago (Tanno and Willcox 2006) from one, or more, rare independent hybridization events between tetraploid emmer wheat (Triticum dicoccoides; $2 n=$ $4 x=28, \mathrm{AABB})$ and the diploid grass Aegilops tauschii $(2 n=2 x=$ 14 , DD) (Nesbitt and Samuel 1996). Wheat provides one-fifth of the calorie intake of the world's human population and is therefore a major contributor to global food security (Food and Agriculture (FAO) 2015). However, fungal diseases are a significant factor impacting cereal production, and for wheat the three rusts; leaf

${ }^{\dagger}$ Corresponding author: C. M. Zanella; E-mail: camila.zanella@niab.com

Funding: This study was supported by Bilateral BBSRC-Embrapa grant number BB/N01622X/1.

First and second authors contributed equally to this work.

*The $\boldsymbol{e}$-Xtra logo stands for "electronic extra" and indicates that four supplementary tables and one supplementary appendix are published online. (brown), stripe (yellow), and stem (black) rust, caused by Puccinia triticina, $P$. striiformis f. sp. tritici, and $P$. graminis f. sp. tritici, respectively, are major global problems.

References to wheat rust are found in the Old Testament of the Bible and in ancient Roman text, indicating historically the extent to which these diseases have been a problem for cereal production (Chester 1943; Levine 1919). While stem and stripe rust are considered more damaging than leaf rust, leaf rust (Fig. 1) is more persistent and widespread, making it a significant problem yearon-year (Huerta-Espino et al. 2011). Yield losses in wheat from $P$. triticina infections are usually the result of decreased numbers of seeds per spike and lower seed weight (Huerta-Espino et al. 2011). Currently, fungicides are widely used to control wheat rusts. However, in many countries limited access to appropriate fungicides and inappropriate application can seriously affect the efficacy of the fungicide, while also having negative consequences on human health and the environment and increasing production costs (Kumar et al. 2013). Consequently, the introduction of effective and potentially durable genetic resistance into new wheat varieties is the preferred approach to rust control, providing a more effective, economic and environmentally friendly approach (Singh et al. 2000). A glossary of the terms used in this review to describe the phenotypic differences between rust resistance loci can be found in Table 1 . 


\section{LEAF RUST RESISTANCE IN WHEAT}

Many wheat loci conferring resistance to the three rust pathogens have been reported (see McIntosh et al. 1995, 2008). Those leaf rust resistance loci that have been determined as unique, being genetically distinct from pre-existing loci, are designated an $L r$ number. However, the majority of leaf rust resistance genes assigned an $L r$ gene number confer all-stage resistance (ASR) (Table 1). ASR is effective throughout the life of the plant. It is commonly qualitative (also referred to as major resistance) and associated with a programmed cell death defense response referred to as hypersensitive immunity. However, ASR often proves to be race-specific; the resistance only being effective against $P$. triticina isolates carrying the corresponding avirulence gene, and short-lived; high levels of mutation and virulence diversity present within $P$. triticina populations resulting in these leaf rust resistance genes rapidly becoming ineffective (Lowe et al. 2011). Consequently, wheat cultivars with long-lasting leaf rust resistance has been hard to achieve using ASR genes alone. Many leaf rust ASR genes have proven ineffective within a few years of introduction, for example, the deployment of $\mathrm{LrlO}$ and Lr16 in Canadian wheat cultivar Selkirk ( Lr10, Lrl4a, and Lr16).

FIGURE 1

Modified Cobb scale leaf rust infection scores on wheat cultivar Toropi.

A, Resistant reaction (40R/3MR), B, moderate resistant reaction (40MR), C, moderate susceptible reaction (70MS), and D, susceptible reaction (100S)

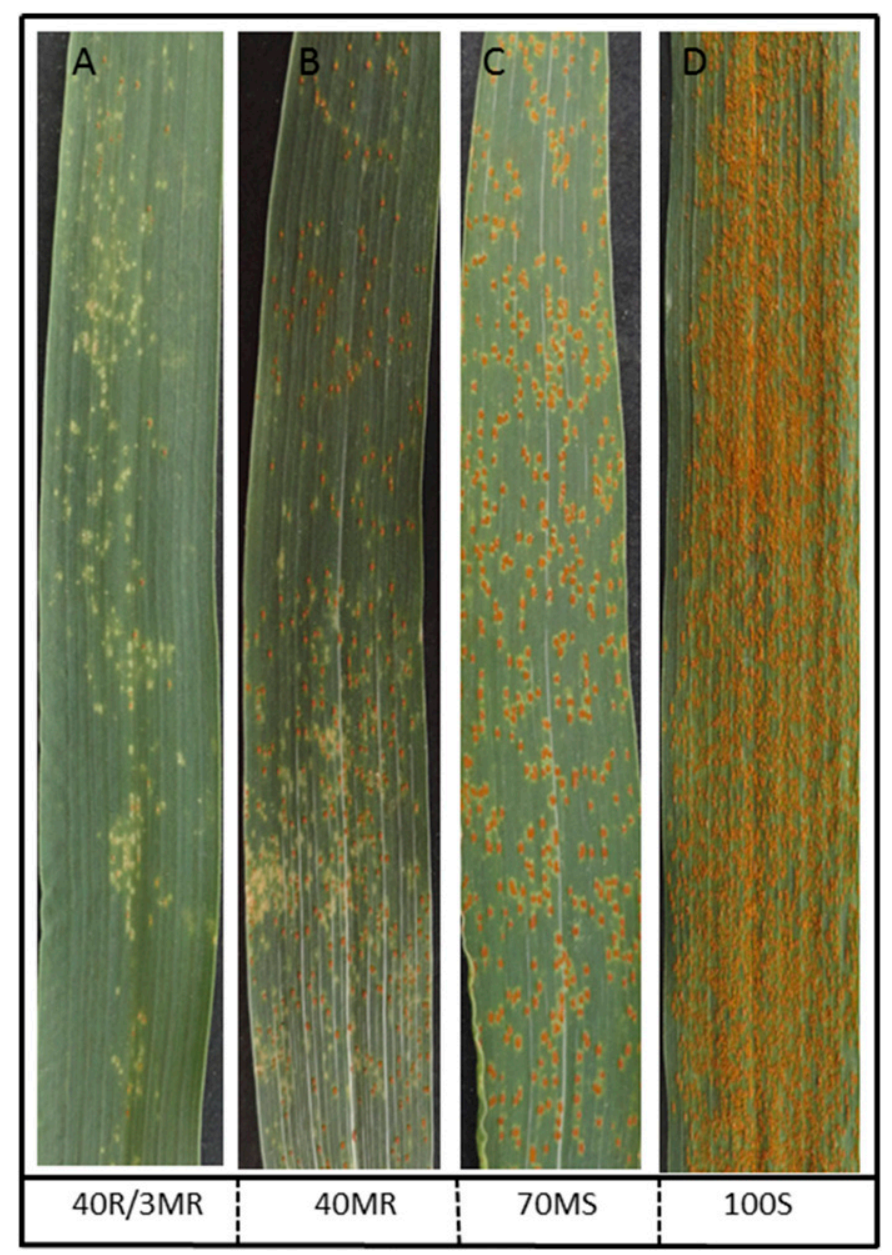

TABLE 1

A glossary of the terms commonly used to describe the phenotypic differences between rust resistance loci

\begin{tabular}{ll}
\hline Adult plant resistance & $\begin{array}{c}\text { Resistance that is not expressed at the two to three leaf seedling stage, but is expressed only at later stages in } \\
\text { the plant's development }\end{array}$ \\
\hline All stage resistance & Resistance that is expressed throughout the life of the plant \\
\hline Partial resistance & Resistance that only confers a partial reduction in pathogen infection \\
\hline Qualitative resistance & Resistance in which the expression is not influenced by genetic background or environmental variables \\
\hline Quantitative resistance & Resistance in which the expression can be influenced by genetic background or environmental variables \\
\hline Quantitative trait loci & The position in the plant genome where loci are found that confer a quantitative resistance \\
\hline Race-non-specific resistance & Resistance that is effective against all known isolates of a pathogen \\
\hline Race-specific resistance & Resistance that is effective against isolates of a pathogen carrying the corresponding avirulence gene \\
\hline Slow rusting resistance & $\begin{array}{l}\text { Resistance that slows the development of pathogen infection, extending the latent period and usually resulting } \\
\text { in smaller pustules and fewer spores }\end{array}$ \\
\hline
\end{tabular}


Virulence to $\mathrm{Lr} 10$ increased soon after the introduction of Selkirk, whereas virulence to $L r 16$ started to increase 8 years after Selkirk was widely grown (McCallum et al. 2016). Combining ASR genes can prolong the effective life of rust resistant cultivars, but this runs the risk of creating races of rust isolates with multiple virulence, leading to hypervirulent pathogen populations.

Currently 15 leaf rust adult plant resistance (APR) genes have been given an $L r$ gene number designation. Seven $L r$ genes, $L r 12, L r 13, L r 22 a / b, L r 35, L r 37, L r 48$, and $L r 49$ have proven to be race-specific, while the remaining eight are still considered race-non-specific (Table 2) (McIntosh et al. 1995, 2008). The race-specific APR genes $L r 12, L r 13$, and $L r 22 b$ are qualitative and associated with a hypersensitive cell death response but expressed only at later stages in the plant's development (McIntosh et al. 2008; Singh and Bowden 2011). A number of APR genes, while conferring only partial leaf rust resistance, have remained effective when deployed widely, for many years and in environments conducive to leaf rust. For example, the APR gene Lr34 has proven to be durable, having been widely deployed in CIMMYT spring wheat cultivars (Singh et al. 2000). Lr34 and Lr46, as well as APR Lr67 are unique in that they confer partial resistance to all three rust species, as well as to powdery mildew, caused by Blumeria graminis f. sp. tritici. In addition, a number of these APR genes also exhibit a slow rusting phenotype, e.g., Lr34. The resistance retards the development of the pathogen (increased latent period) (Table 1), slowing the appearance of rust pustules, which generally tend to be smaller and produce fewer urediniospores (Singh et al. 2005).

The potential of APR to confer durable protection against the cereal rusts has gained great attraction since the pioneering work of R. M. Caldwell in the US and R. Johnson in the UK; work that today serves as a guiding principle in many research and breeding programs. The renewed interest in APR genes has accelerated the discovery of new quantitative trait loci (QTL) (Table 1), many conferring resistance toward all three rust pathogens of wheat (Lowe et al. 2011). However, a single QTL rarely confers adequate resistance, especially under high disease pressure, a combination of four or five QTL/genes being required to establish adequate levels of rust resistance (Singh et al. 2000). It is also important to understand how environmental variables impact each QTL's expression, and how the QTL interact, either positively or negatively, to influence the final rust resistant phenotype. Therefore, in quantifying the value of a QTL for rust resistance breeding it is important to consider the QTL's expression over a range of environments, across seasons and under different levels of disease pressure.

In this review we focus on quantitative leaf rust resistance in hexaploid wheat, as identified through field tests. The review covers reports published between January 1971 and January 2018, and references 249 leaf rust resistance QTL. We review leaf rust resistance QTL identified in biparental and association mapping (AM) studies and compare with a QTL meta-analyses for leaf rust resistance published in 2015 (Soriano and Royo 2015). The aims of this review are therefore to summarize field, APR QTL for leaf rust.

\section{QUANTITATIVE RACE-NON-SPECIFIC APR LOCI WITH LR DESIGNATIONS}

Lr34/Yr18/Sr57/Pm38 (hereafter called Lr34) was first characterized in Canada by Dyck (1977, 1987), but Lr34-containing wheat germplasm has been used in the development of new wheat cultivars since the early part of the twentieth century. While the Lr34 resistant phenotype can vary in different environments and genetic backgrounds, Lr34 has remained durable for more than 50 years (Krattinger et al. 2009; Lagudah et al. 2009). Lr34 was the first APR gene to be cloned (Krattinger et al. 2009). It encodes an ATP-binding cassette (ABC) transporter and currently two predominant alleles of Lr34 have been found that differ by only two exon-polymorphisms (Krattinger et al. 2009; Lagudah et al. 2009). Three other haplotypes were described for Lr34, two being considered rare (Dakouri et al. 2010; Lagudah et al. 2009). Studies suggest that the resistant haplotypes are evolutionarily younger than the susceptible, and that it is unique to the wheat D-genome; Lr34 being located on the short arm of chromosome 7D. Cloning of Lr34 has enabled gene-specific DNA markers to be developed (Dakouri et al. 2010; Krattinger et al. 2009; Lagudah et al. 2009), providing a fast and powerful tool for marker assisted selection (MAS) in wheat breeding, allowing Lr34 to be combined with other QTL and/or genes of interest.

Lr46/Yr29/Sr58/Pm39 (hereafter called Lr46) has been found extensively in wheat germplasm originating from CIMMYT (William et al. 2003). This gene is located on the long arm of chromosome 1B, being first identified in wheat cultivar Pavon 76 (Singh et al. 1998). Lr46 was mapped distal to marker Xwmc44 and proximal to Xgwm259 in wheat cultivar Oligoculm (Suenaga et al. 2003) and between the SSR markers Xwmc719 and Xhbe 248 in cultivar Saar (Lillemo et al. 2008). The csLV46 marker (E. S. Lagudah, personal communication/unpublished data) is being used in MAS for the Lr46 locus. While Lr46 has a similar phenotype to Lr34, conferring multiple-pathogen resistance (Lillemo et al. 2008; William et al. 2003), the resistance conferred by Lr46 is not as pronounced as Lr34 in some environments (Kolmer et al. 2018a; Lagudah 2011).

The leaf rust APR gene $L r 67 / Y r 46 / S r 55 / P m 46$ (hereafter called Lr67) was first identified in the Pakistan wheat accession PI250413

TABLE 2

List of adult plant resistance (APR) genes with designated leaf rust numbers identified in hexaploid wheat (Triticum aestivum) and currently considered race-non-specific

\begin{tabular}{|c|c|c|c|}
\hline APR $L r$ gene & Chromosome & Cultivars & Reference \\
\hline Lr46 & $1 \mathrm{BL}$ & Pavon 76 & Singh et al. 1998 \\
\hline Lr68 & 7BL & Parula/Frontana & Herrera-Foessel et al. 2012 \\
\hline$L r 74$ & 3BS & BT-Schomburgk & Chhetri 2016 \\
\hline$L r 77$ & $3 B L$ & Santa Fe & Kolmer et al. $2018 \mathrm{~b}$ \\
\hline Lr78 & 5DS & Toropi & Kolmer et al. 2018a \\
\hline
\end{tabular}


and transferred into Thatcher to produce the near-isogenic line RL6077 (Thatcher*6/PI250413) (Dyck and Samborski 1979). Hiebert et al. (2010) mapped Lr67 in RL6077 to the long arm of chromosome 4D. Lr67 can be found in Indian wheat cultivar Sujata (Lan et al. 2015) and NewPusa876 (Ponce-Molina et al. 2018b), and the CIMMYT cultivars Yaqui53, Chapingo48 and Chapingo53 (Moore et al. 2015). Lr67 has been cloned, the protein resembling a predicted hexose transporter (LR67res). Although both the resistant, Lr67res and susceptible allele, Lr67sus are upregulated upon rust infection, only Lr67res confers resistance. LR67res differs from LR67sus by two amino acids in a region conserved across orthologous hexose transporters, which in turn reduces the proteins affinity for glucose. LR67res exerts a dominant-negative effect through heterodimerization, which is thought to reduce glucose uptake, thereby inhibiting colonization of plant tissues by biotrophic pathogens (Moore et al. 2015). Cloning of Lr67 has enabled gene-specific DNA markers to be developed for MAS (Moore et al. 2015).

Other leaf rust APR genes that have been sufficiently characterized to be designated a $\operatorname{Lr}$ number include $\operatorname{Lr} 68, \operatorname{Lr} 74, \operatorname{Lr} 75, \operatorname{Lr} 77$, and $L r 78$. $L r 68$ is an APR gene that was mapped on the long arm of chromosome 7B (Herrera-Foessel et al. 2012). Its origins can be traced back to Brazilian cultivar Frontana, which also possesses Lr34 and Lr13. The markers Psyl-1 (0.5 cM) and Xgwm146 (0.6 cM) flank the Lr68 locus but were not suitable for MAS (HerreraFoessel et al. 2012). The codominant marker $c s 7 B L N L R R(0.8 \mathrm{cM})$ and the dominant marker $\operatorname{cs} G S(1.2 \mathrm{cM})$ have subsequently been developed for Lr68 (Herrera-Foessel et al. 2012).

Lr74 is an APR on chromosome arm 3BS, originally mapped in wheat selection BT-Schomburgk and cultivar Spark, it has also been found in wheat cultivar Caldwell (Kolmer et al. 2018c). The leaf rust APR $L r 75$ is located on the short arm of chromosome 1B, first identified in Swiss cultivar Forno (Singla et al. 2017). Schnurbusch et al. (2004) reported six leaf rust resistance QTL in Forno, including Lr34. The locus QLr.sfr-1BS (Lr75) explained from 28 to $32 \%$ of the phenotypic variation when grown in Switzerland. A re-evaluation of the original mapping population from the cross Arina $\times$ Forno resulted in the designation of QLr.sfr$1 B S$ as $\operatorname{Lr} 75$ (Singla et al. 2017).

Lr77 was identified in hard red wheat winter cultivar Santa Fe on the long arm of chromosome 3B (Kolmer et al. 2018b). The locus is defined by the SNP marker IWB10344 and confers $r^{2}$ values from 0.23 to 0.79 . $L r 78$ was identified in Brazilian cultivar Toropi on the short arm of chromosome 5D, designated by the SNP marker IWA6289. $\operatorname{Lr} 78$ confers $r^{2}$ values up to 0.53 for leaf rust resistance (Kolmer et al. 2018a).

While these APR genes confer partial resistance, in combination with other APR genes, or ASR genes, greater resistance can be achieved. For example, the APR gene $L r 46$, in combination with the QTL QLr.cdl-5BL exhibited enhanced, additive resistance (Kolmer 2015). The ASR genes Lrl6 and Lr23, in combination with Lr34, have conferred effective leaf rust resistance for several years in hard red wheat cultivar Norm, even though alone these genes do not provide a significant level of resistance (Kolmer 2015; Tsilo et al. 2014). A complementary combination of ASR and APR genes is usually considered the most desirable for providing effective leaf rust resistance in the field, while potentially maintaining resistance durability (Lagudah 2011).

\section{IDENTIFICATION OF LEAF RUST RESISTANCE QTL}

A QTL is defined at a position in the genome where a gene/s is found that confers a quantitative phenotype, the expression of the gene being potentially influenced by other genes in the genetic background, e.g., epistatic interactions, and/or environmental factors (Table 1) (Lynch and Walsh 1998). QTL identification requires a plant population where the QTL are represented by different alleles, each conferring a detectable, but different phenotype. The QTL is called when the mean resistance phenotype between plants carrying different alleles at that locus are significantly different. The population must also be sufficiently genetically diverse to enable polymorphic DNA markers associated with the QTL to be identified. Several populations types have been utilized for mapping of leaf rust resistance QTL, including $\mathrm{F}_{2}$, backcrosses $(\mathrm{BC})$, doubled haploid (DH), recombinant inbred line (RIL), near-isogenic line (NIL), multiparent advanced generation intercrosses (MAGIC), and association mapping (AM) populations. Each population type possesses advantages and disadvantages. In mapping populations derived from biparental crosses QTL detection is limited by the trait genetic diversity present within the two parents of the original cross (Xu et al. 2017). In addition, they usually represent limited recombination events, allowing the localization of QTL, at best to 10 to $20 \mathrm{cM}$ intervals (Xu et al. 2017). Multiparent mapping populations have been constructed to overcome the limitations of biparental populations. The multiple genotypes (parents) used to develop the population allows the inclusion of multiple QTL, and QTL alleles, while repeated cycles of crossing increases the number of recombination events, allowing for greater mapping resolution.

To date most leaf rust resistance QTL have been identified using biparental mapping populations. More recently, AM panels have been used to widen the germplasm search for leaf rust resistance QTL. AM has enormous potential to process large collections of diverse germplasms, but usually requires followon confirmation, often through biparental mapping, to validate MTA (Prins et al. 2016). AM relies on the linkage between genes and molecular markers having been broken by many generations of recombination, with any remaining associations being due to close physical proximity. AM therefore overcomes two fundamental limitations of biparental mapping: the limited amount of recombination that occurs during the development of a biparental mapping population, which in turn influences the resolution of QTL positions, and the limited allelic diversity that segregates within a biparental cross. However, AM is prone to false positive QTL identification due to population structure and cannot detect rare alleles $(<5 \%)$ within the AM panel (Korte and Farlow 2013).

The advances in DNA marker technologies mean that it is now possible to obtain good genetic maps for large genome species such as hexaploid wheat, with good marker coverage of most chromosomes, although the D-genome is still underrepresented due to low levels of DNA polymorphism (Gao et al. 2016; Li et al. 2015). With the 66 leaf rust resistance studies reviewed, we observed that SSR markers are still a popular choice in wheat due to their good coverage of the genome, codominant inheritance, high information content, simple detection and reproducibility (Supplementary Table S1). SSR markers are also a good marker to compare between genetic maps. However, SSRs are now being superseded in leaf rust resistance mapping studies by advanced, next-generation-sequencing (NGS) SNP marker technologies (Chhetri et al. 2016; Ponce-Molina et al. 2018a), including the use of the Illumina iSelect $9 \mathrm{~K}$ and $90 \mathrm{~K}$ SNP arrays (Zhang et al. 2017). These new marker technologies, along with the release of the hexaploid wheat RefSeq-v1.0 genome (https://www.wheatgenome.org/), provide accurate methodologies for locating QTL and comparing QTL locations across wheat genotypes.

Several statistical methods have been developed to detect QTL (Hackett 2002). A QTL is defined by its position on a genetic marker linkage map (centimorgans; cM), by its $r^{2}$ value (percentage of phenotypic variation explained - \% PVE) and it's LOD (logarithm of the odds) score. The value of $r^{2}$ shows the influence of the QTL on the phenotype, being the percent of the total phenotypic variance that is accounted for by the QTL associated markers. The LOD score is the statistical strength of 
evidence for a QTL at a given location (Broman 2001). The term "major QTL" is often used to indicate that a QTL has a large effect on the phenotype and is usually detected in more than one environment. Some authors consider a QTL as "major" when it contributes at least 15 to $20 \%$ of the phenotypic variation segregating in the test population (Du et al. 2015). However, the same QTL can contribute differently to the phenotypic variance in different studies; i.e., different populations and growing environments.

\section{SUMMARY OF REPORTED LEAF RUST APR QTL}

In this review we report on 249 leaf rust resistance QTL as identified in 70 biparental mapping populations and 79 different donor lines, 35 meta-QTL (MQTL) (Supplementary Table S2) reported by Soriano and Royo (2015), and nearly 200 MTA/QTL (marker trait associations) identified in seven AM studies, covering all 21 chromosomes of hexaploid wheat (Table 3; Supplementary Table S3). The last review on this topic, Li et al. (2014), reviewed 27 studies in durum and bread wheat, reporting 80 leaf rust APR loci across 16 chromosomes (highlighted in bold in Supplementary Table S1).

An MQTL analysis was carried out by Soriano and Royo (2015) that incorporated 144 leaf rust resistance QTL identified in 20 biparental mapping populations. The mapping populations represented 33 parental lines, both bread and durum wheat cultivars, studied between 1999 and 2015 in 52 environments. This MQTL analysis integrated the results of these independent QTL studies, projecting the individual QTL onto a consensus map using QTLassociated markers common between the mapping populations
(Goffinet and Gerber 2000). Pooling the results of several studies through MQTL analysis increases statistical power and allows more precise estimation of genetic effects (Wu and $\mathrm{Hu} 2012$ ). The MQTL analysis identified 48 regions, on 17 chromosomes, 35 of which represented two or more, closely linked leaf rust resistance QTL (128 QTL out of 144 QTL included in the meta-analysis), with the remaining 13 regions containing a unique QTL. Seven of the MQTL were found to colocalize with 11 designated $L r$ genes (Lr10, Lr13, Lr14, Lr19, Lr23, Lr27, Lr34, Lr46, Lr67, Lr68, and Lr71) (Soriano and Royo 2015).

Leaf rust resistance AM studies have been undertaken in 96 winter wheat genotypes (Gerard et al. 2018), 3,640 spring wheat genotypes (Elbasyoni et al. 2017; Gao et al. 2016; Kankwatsa et al. 2017; Turner et al. 2017), 295 mixed-type wheat genotypes (Riaz et al. 2018), and 173 synthetic hexaploid wheat genotypes (Jighly et al. 2016). These studies reported 175 MTA/QTL across 20 wheat chromosomes, with no associations reported on chromosome 3D (Table 3).

The B genome carries the greatest number of leaf rust resistance QTL (Fig. 2; Supplementary Table S4), with 133 QTL, mainly on chromosomes 1B and 2B (Fig. 2). Approximately 53\% of the 249 QTL and 20 MQTL reported in biparental mapping studies are located on the $\mathrm{B}$ genome. The $\mathrm{A}$ genome has the lowest number of QTL for leaf rust resistance. Chromosomes 4A, 7A, 5D, and 6D have the fewest leaf rust resistance QTL (Fig. 2). The group 2 chromosomes carry 66 leaf rust resistance QTLs and 6 MQTL, with chromosome $2 \mathrm{~B}$ also being well known for carrying disease resistance loci for stripe rust, stem rust, and powdery mildew (McIntosh et al. 1995, 2008).

TABLE 3

Summary of significant leaf rust resistance marker trait associations identified in hexaploid wheat by association mapping (AM)

\begin{tabular}{|c|c|c|c|c|c|c|c|c|}
\hline Genomic source & $\begin{array}{l}\text { Number of } \\
\text { genotypes }\end{array}$ & $\begin{array}{l}\text { Type of } \\
\text { resistance } \\
\text { assayed }\end{array}$ & $\begin{array}{l}\text { Number of } \\
\text { polymorphic } \\
\text { markers }\end{array}$ & $\begin{array}{l}\begin{array}{c}\text { Number } \\
\text { of } \\
\text { MTA/QTL }\end{array}\end{array}$ & $\begin{array}{l}\text { Chromosome } \\
\text { location }\end{array}$ & $\begin{array}{c}\text { Genes } \\
\text { predicted }^{\mathrm{a}}\end{array}$ & $\begin{array}{l}\text { Genotyping } \\
\text { technology }\end{array}$ & Reference \\
\hline Spring wheat & 2,111 & Adult & 3,215 & 36 & $\begin{array}{c}1 \mathrm{~A}, 2 \mathrm{~A}, 2 \mathrm{~B} \\
2 \mathrm{D}, 3 \mathrm{~A}, 5 \mathrm{~A} \\
5 \mathrm{~B}, 6 \mathrm{~A}, 7 \mathrm{~A} \\
\end{array}$ & $\begin{array}{l}\operatorname{trp}-1, \operatorname{Lr} 11 \\
\quad \text { Lr52, Lr47 }\end{array}$ & $\begin{array}{l}\text { Illumina iSelect } \\
9 \mathrm{~K} \text { SNP array }\end{array}$ & $\begin{array}{l}\text { Elbasyoni et al. } \\
2017\end{array}$ \\
\hline $\begin{array}{l}\text { Elite spring } \\
\text { wheat } \\
\text { breeding lines }\end{array}$ & 338 & $\begin{array}{l}\text { Seedling } \\
\text { and adult }\end{array}$ & 18,924 & 46 & $\begin{array}{l}\text { All (except 3D } \\
\text { and 5A) }\end{array}$ & $\begin{array}{l}\text { Lr1, Lr3, Lr9, } \\
\text { Lr11, Lr14, } \\
\text { Lr17, Lr21, } \\
\text { Lr26, Lr28, } \\
\text { Lr30, Lr34, } \\
\text { Lr38, Lr42, } \\
\text { Lr64, Lr68, } \\
\text { Lr72 }\end{array}$ & $\begin{array}{l}\text { Illumina iSelect } \\
\text { 90K SNP } \\
\text { array }\end{array}$ & $\begin{array}{l}\text { Gao et al. } \\
\quad 2016\end{array}$ \\
\hline Winter wheat & 96 & Adult & 874 & 13 & $\begin{array}{c}1 \mathrm{~B}, 1 \mathrm{D}, 2 \mathrm{~A} \\
2 \mathrm{~B}, 2 \mathrm{D}, 3 \mathrm{~B} \\
4 \mathrm{~A}, 5 \mathrm{~B} / 7 \mathrm{~B} \\
6 \mathrm{~A} / 6 \mathrm{~B}, 7 \mathrm{D}\end{array}$ & $\begin{array}{l}\text { Lr22, LrSV1, } \\
\text { Lr27/Sr, } \\
\text { LrSV2, Lr28/ } \\
\text { Sr7 }\end{array}$ & DArT & $\begin{array}{l}\text { Gerard et al. } \\
2018\end{array}$ \\
\hline $\begin{array}{l}\text { Synthetic } \\
\text { hexaploid } \\
\text { wheat }\end{array}$ & 173 & Adult & 6,176 & 5 & $\begin{array}{c}1 \mathrm{~B}, 1 \mathrm{D}, 2 \mathrm{D} \\
6 \mathrm{D}, 7 \mathrm{D}\end{array}$ & $\begin{array}{l}\text { Lr46, Lr42, } \\
\text { Lr39, Lr38, } \\
\text { Lr19 }\end{array}$ & $\begin{array}{l}\text { DArT and } \\
\text { DArT-Seq }\end{array}$ & $\begin{array}{l}\text { Jighly et al. } \\
2016\end{array}$ \\
\hline Spring wheat & 159 & $\begin{array}{l}\text { Seedling } \\
\text { and adult }\end{array}$ & 5,688 & 23 & $\begin{array}{c}1 \mathrm{~B}, 1 \mathrm{D}, 3 \mathrm{~B} \\
4 \mathrm{~A}, 5 \mathrm{~B}, 6 \mathrm{~A} \\
6 \mathrm{~B}, 6 \mathrm{D}, 7 \mathrm{~A} \\
\end{array}$ & $\begin{array}{l}\text { Lr34, Lr46, } \\
\text { Lr67, Lr68, } \\
\text { Lr74 }\end{array}$ & $\begin{array}{l}\text { Illumina iSelect } \\
9 \mathrm{~K} \text { SNP array }\end{array}$ & $\begin{array}{l}\text { Kankwatsa } \\
\text { et al. } 2017\end{array}$ \\
\hline Hexaploid wheat & 295 & $\begin{array}{l}\text { Seedling } \\
\text { and adult }\end{array}$ & 10,748 & 31 & $\begin{array}{l}\text { 1A, 1B, 2A, } \\
2 B, 3 A, 3 B \\
4 A, 5 A, 5 B \\
6 A, 6 B, 7 A \\
7 B, 7 D\end{array}$ & $\begin{array}{l}\text { Lr64, Lr3, } \\
\text { Lr14b, Lr68, } \\
\text { LrBi16, } \\
\text { LrFun, Lr34 }\end{array}$ & DArT-Seq & $\begin{array}{l}\text { Riaz et al. } \\
\quad 2018\end{array}$ \\
\hline Spring wheat & 1,032 & $\begin{array}{l}\text { Seedling } \\
\text { and adult }\end{array}$ & 5,732 & 37 & $\begin{array}{l}\text { All (except 1D, } \\
\text { 3D, 6B, and } \\
\text { 7B) }\end{array}$ & $\begin{array}{l}\text { Lr10, Lr11, } \\
\text { Lr17, Lr27, } \\
\text { Lr28, Lr30, } \\
\text { Lr34, Lr35, } \\
\text { Lr46, Lr63, } \\
\text { Lr66, Lr67, } \\
\text { Lr74 }\end{array}$ & $\begin{array}{l}\text { Illumina iSelect } \\
9 \mathrm{~K} \text { SNP array }\end{array}$ & $\begin{array}{l}\text { Turner et al. } \\
2017\end{array}$ \\
\hline
\end{tabular}

a Genes with no leaf rust resistance considered by the authors to be present in their AM germplasm. 
The B genome is the largest of the wheat genomes and is highly diverged from the A and D genomes. The three ancestral genomes, although genetically related, i.e., homoelogous chromosomes capable of pairing at meiosis, have undergone considerable divergence and modifications since the first hexaploid was formed (Griffiths et al. 2006). The D genome shows the least differentiation relative to its progenitor A. tauschii, but in hexaploid wheat the D genome exhibits limited DNA polymorphism, presumably due to limited polyploidization events with tetraploid emmer wheat (Triticum dicoccoides; AABB) during its evolution (Nesbitt and Samuel 1996). However, the D genome donor is still available, A. tauschii having a geographic distribution that extends from northeastern Syria, Iran, Iraq, and Transcaucasia, to the western slopes of the Himalayas into China, and therefore represents a potential source of wide genetic diversity that could be introduced into hexaploid wheat (Haider 2013). The precise ancestor of the wheat B genome is unknown (Haider 2013). The A genome donor is believed to have been related to the diploid wild einkorn wheat Triticum urartu, although considerable gene loss has been reported on the A genome of hexaploid wheat compared with T. urartu (Ling 2013). This gene loss may explain why the A genome has so few leaf rust resistance loci compared with the $\mathrm{B}$ and $\mathrm{D}$ genomes in hexaploid wheat.

In the remainder of this review we describe the leaf rust resistance QTL identified in biparental mapping studies and the meta-analysis by chromosome group. The \% PVE by each QTL is provided to give the reader an idea of the possible "strength" of the leaf rust resistance, although it must be remembered that other factor can influence the \% PVE of a QTL, including the other leaf rust resistance genes segregating in the population in which the QTL was identified. Although QTL may appear to locate to what appears to be the same chromosome position, this could not be confirmed for most studies, as different marker systems have been used over the period being reviewed. Where QTL were reported as colocating with designated $L r$ genes we could ascertain that the same leaf rust resistance QTL was being reported, e.g., for $\operatorname{Lr} 34$ (7DS) (Fig. 2).

\section{CHROMOSOME GROUP 1 LINKED QTL}

Chromosomes 1A, 1B, and 1D homeologs possess 48 QTL and five MQTL, of which 11 QTL are located on chromosome 1A, 32 on chromosome 1B and 5 on chromosome 1D (Fig. 2). One MQTL was found on $1 \mathrm{~A}$ and four on $1 \mathrm{~B}$ (Fig. 2). The $11 \mathrm{QTL}$ and one MQTL reported on chromosome $1 \mathrm{~A}$ are derived from the wheat genotypes Apache, Opata 85, 842-2, Syn022L, Chapio, Shanghai 3/Catbird, Luke, and Sujata (Azzimonti et al. 2014; Du et al. 2015; Kumar et al. 2013; Lan et al. 2015; Leonova et al. 2008; Naz et al. 2008; Rosewarne et al. 2015; Zhou et al. 2014). QLr.cau-1AS explained from 44.3 to $52.6 \%$ PVE for leaf rust in wheat cultivar Luke when crossed with Aquileja, but only explained 22.3 to $32.8 \%$ PVE when crossed with AQ24788-83 (Du et al. 2015). RIL carrying QLr.cau$1 A S$, when grown in China (Beijing, Gansu and Shandong) exhibited a $55.5 \%$ reduction in final leaf rust severity compared with control lines. RIL possessing QLr.cau-1AS in combination with $\operatorname{Lr} 34$ showed around a $78.5 \%$ reduction in final rust severity (Du et al. 2015). The MQTL1 on chromosome 1A colocalized with the ASR gene LrlO (Soriano and Royo 2015).

Lr46, on the long arm of chromosome 1B, is common in CIMMYT wheat germplasm (Lan et al. 2014; Rosewarne et al. 2012). Lr46 confers broad-spectrum resistance to four biotrophic fungal pathogens: P. triticina (Lr46), P. striiformis (Yr29), P. graminis f. sp. tritici (Sr58) (Singh et al. 2013), and Blumeria graminis f. sp. tritici (Pm39) (Lillemo et al. 2008). The locus is also associated with premature senescence of leaf tips, commonly referred to as leaf tip necrosis ( $L t n 2)$ (Rosewarne et al. 2006). Lr46 was reported in 20 studies from 19 wheat donor genotypes. In 13 studies Lr46 was associated with the marker $c s L V 46$, which is used in MAS for $L r 46$. Based on the presence of the marker $c s L V 46$ we considered a QTL to be a good candidate for Lr46 (Fig. 2). However,

- Total QTL $\quad$ Unique QTL $\quad$ MQTL

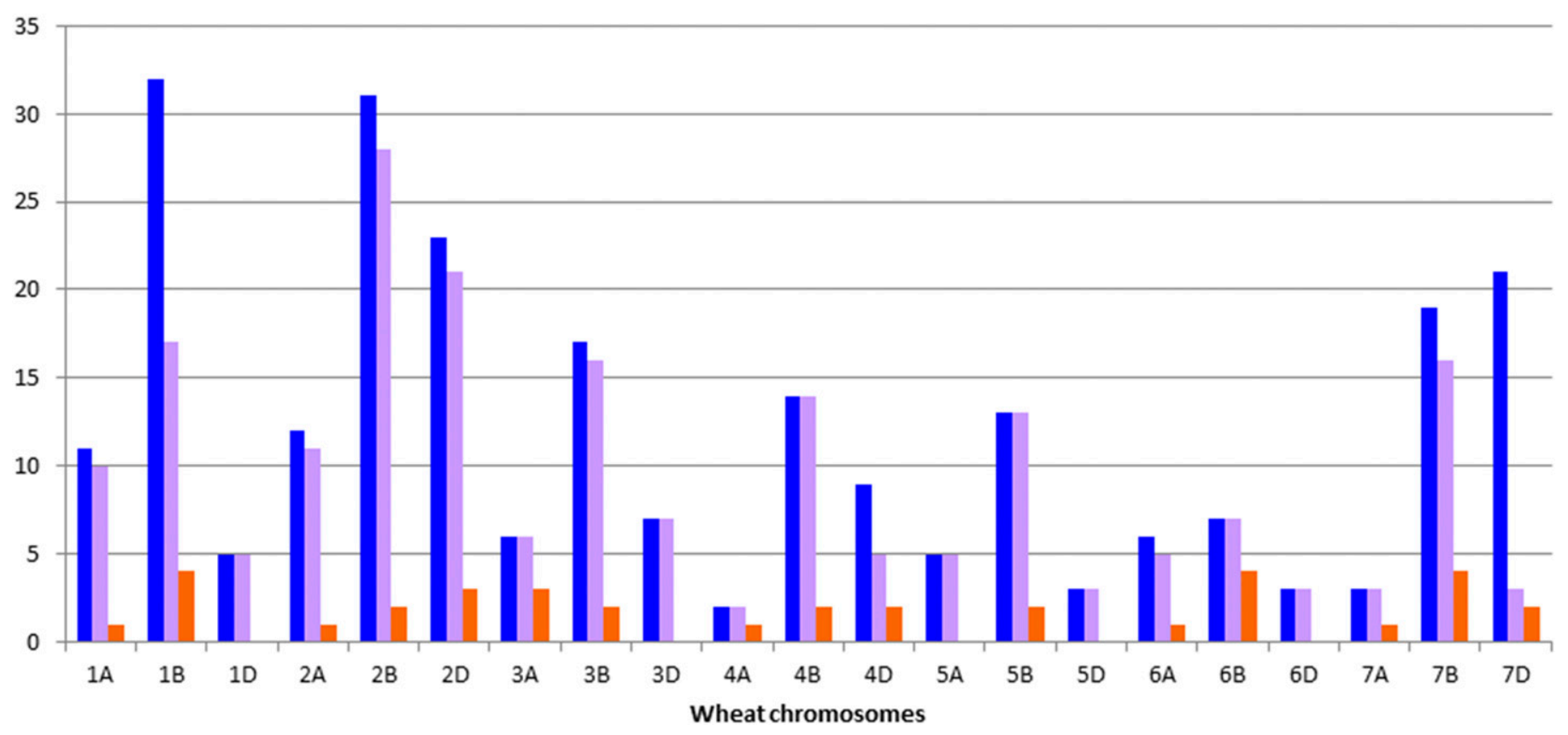

FIGURE 2

Total number of leaf rust resistance quantitative trait loci (QTL) found on each hexaploid wheat chromosome, as reported in 70 biparental mapping studies (dark blue columns) and one leaf rust QTL meta-analysis (MQTL; orange columns). Some QTL may be reported more than once, as different markers were used in each mapping study, making comparison of genome locations difficult. Where we were able to confidently identify QTL in independent studies as having the same chromosomal location, we report the unique QTL number on each chromosome (purple columns). 
the effectiveness of $L r 46$ depends greatly upon the genetic background and environment (Lan et al. 2015), being less effective at higher temperatures (Lagudah 2011; Rosewarne et al. 2015). Lr46 explained from 2.9 to $74.5 \%$ of the total PVE in different mapping populations and under different experimental conditions. The MQTL5 on 1B colocalized with the APR gene Lr46 (Soriano and Royo 2015). The APR Lr75 (QLr.sfr-1BS) also mapped to chromosome 1B, but to the short arm, and is flanked by SSR loci X $g w m 604$ and Xswm27 (Singla et al. 2017). $L r 75$ explained 28 to $32 \%$ PVE in the cross Arina $\times$ Forno when grown in Switzerland (Schnurbusch et al. 2004).

Five QTL have been reported on chromosome 1D in four studies, derived from the wheat genotypes Syn022L, Avocet-YrA, Quaiu 3, and Kenya Kongoni (Basnet et al. 2014; Calvo-Salazar et al. 2015; Naz et al. 2008; Ponce-Molina et al. 2018a). Two of these QTL were subsequently identified as the ASR genes $L r 21$ and Lr42 (Basnet et al. 2014; Naz et al. 2008). Working with a BC population derived from the synthetic wheat Syn022L, Naz et al. (2008) found a QTL on chromosome 1D that mapped close to the marker locus Xbarc 149. This QTL conferred both seedling (QLrs. $B 22-1 D)$ and field leaf rust resistance $(Q L r . B 22-1 D)$, reducing leaf rust symptoms by 46.3 and $43.6 \%$, respectively (Naz et al. 2008). Although the seedling QLrs.B22-1D located to the same chromosomal region as $L r 21$, different seedling phenotypes were observed when inoculated with the same $P$. triticina isolate. This would indicate either a new allele of $L r 21$, or a new ASR gene, independent, but located near Lr21 (Naz et al. 2008).

\section{CHROMOSOME GROUP 2 LINKED QTL}

The group 2 chromosomes homeologs possess the greatest number of leaf rust resistance genes, 66 QTL and six MQTL, with 12 QTL on chromosome $2 \mathrm{~A}, 31$ on chromosome $2 \mathrm{~B}$, and 23 on chromosome $2 \mathrm{D}$, and one MQTL was found on $2 \mathrm{~A}$, two on $2 \mathrm{~B}$ and three on 2D (Fig. 2). To date, around 20 designated $L r$ genes have been mapped to group 2 chromosomes, many being ASR genes (McIntosh et al. 1995, 2008). The APR gene Lr37 was translocated to the short arm of wheat chromosome $2 \mathrm{~A}$ from Triticum ventricosum (Helguera et al. 2003). Qlrinra-2Ab was identified in cultivar Apache, explaining 5.6 to $12.2 \%$ of the PVE and colocated with Lr37 (Azzimonti et al. 2014). QLr.hbau-2AS, derived from cultivar Weimai 8 explained from 25.79 to $71.55 \%$ of PVE and mapped between the marker loci Xcfd36 and Xbarc 1138, within an interval of $2.58 \mathrm{cM}$ (Wang et al. 2015).

There are seven designated $L r$ genes on chromosome $2 \mathrm{~B}$, three of which are the APR genes $L r 13, L r 35$, and $L r 48$, all of which are race-specific genes (McIntosh et al. 2008). Lr35 is located near the centromere, while $\operatorname{Lrl3}$ and $\operatorname{Lr} 48$ are on the short arm of 2B (McIntosh et al. 1995). Lrl3 is no longer effective in Mexico and South America but continues to confer leaf rust resistance in Australia and Canada (Zhang et al. 2016). MQTL8 is a compilation of seven studies, all using wheat cultivars Apache and Creso, and is likely to be associated with $\operatorname{Lr} 13$ (Soriano and Royo 2015). $L r 48$ is a recessive race-specific APR gene that is associated with a hypersensitive response and has been mapped between SSR marker loci Xgwm429b and Xbarc7 (Bansal et al. 2008). Lr35 was transferred to hexaploid wheat from the diploid wild relative $A$. speltoides, and like $L r 48$ confers a hypersensitive reaction upon infection with $P$. triticina (Saini et al. 2002). A major QTL, QLr.hebau-2BS was also mapped on 2BS, but to a different location from $L r 13$ and $L r 48$ (Zhou et al. 2014). QLr. hebau- $2 B S$ was mapped in the cross Shanghai $3 \times$ Catbird, being flanked by loci XwPt8548 and XwPt2314, and conferred from 15.3 to $37.4 \%$ of the PVE. QLr.inra-2B explains from 15 to $35.6 \%$ of the PVE for leaf rust resistance in wheat cultivar Apache but is on the long arm of 2B (Azzimonti et al. 2014).

Chromosome 2D has eight designated $\mathrm{Lr}$ genes, with $\mathrm{Lr} 22 \mathrm{a}$ derived from A. tauschii and $L r 22 b$ derived from T. aestivum conferring race-specific APR (McIntosh et al. 1995, 2008). Of the 23 QTL identified on chromosome 2D the most effective were QLrlp.osu-2DS (wheat breeding line CI 13227) and QLr.inra-2D (cultivar Balance), which explained 34.6 to $48.2 \%$ and 4.4 to $46.4 \%$ of the PVE, respectively (Azzimonti et al. 2014; Xu et al. 2005). QLrlp.osu-2DS exhibits a slow rusting phenotype, having a prolonged latent period. RIL possessing QLrlp.osu-2DS had a mean latent period of 13 days, while lines without the QTL had mean latent periods of 7.5 days.

\section{CHROMOSOME GROUP 3 LINKED QTL}

Seven designated $L r$ genes have been found on the group 3 chromosomes. Five are ASR genes; Lr24, Lr27, Lr32, Lr63, and Lr66 and two APR genes; Lr74 and Lr77 (McIntosh et al. 1995, 2008). There are 30 QTL and five MQTL reported on group 3 chromosomes, six QTL on chromosome 3A, 17 on chromosome $3 \mathrm{~B}$, and seven on chromosome 3D. Three MTQL was reported on chromosome $3 \mathrm{~A}$ and 2 on 3B (Fig. 2). QLr.fcu-3AL, derived from the synthetic hexaploid wheat line TA4152-60, explained between 10 to $18 \%$ of the PVE in field tests, but also exhibited leaf rust resistance in seedling tests, indicating a potential ASR gene (Chu et al. 2009).

On chromosome 3B, QLr.sun-3BS explained 2.4 to $36.7 \%$ of the total PVE in the BT-Schomburgk selection (Chhetri et al. 2016), while QLr.ifa-3BS explained 4.1 to 40.1\% PVE (Buerstmayr et al. 2014) in wheat cultivar Capo. QLr.ifa-3BS also colocated with the stripe rust QTL QYr.ifa-3BS for both RIL populations studied; Capo $\times$ Arina and Capo $\times$ Furor (Buerstmayr et al. 2014). QLr.cin$3 B S$ was mapped in wheat cultivar Chapio and may be the same locus as $\mathrm{Sr} 2$, representing a multipathogen resistance gene (Rosewarne et al. 2015). Kolmer et al. (2018c) mapped an APR QTL on 3B in cultivar Caldwell, which is colocated with the APR gene $L r 74$. Li et al. (2017) also reported a QTL (QLr.hwwg-3B.1) on 3B that explained 16.6 to $19.2 \%$ of PVE and was provisionally identified as $\operatorname{Lr} 74$.

QLr.cim-3DC is the most effective leaf rust APR locus found on chromosome 3D. It explained from 17.8 to $25.4 \%$ of the PVE in wheat cultivar Francolin\#1 (Lan et al. 2014). QLr.tam-3D only explained 4.0 to $7.1 \%$ of the leaf rust PVE in the wheat line Quaiu 3 but did colocate with the yellow rust QTL QYr.tam-3D (Basnet et al. 2014).

\section{CHROMOSOME GROUP 4 LINKED OTL}

Twenty-five QTL and five MQTL have been reported on the group 4 chromosomes (Fig. 2). Two QTL were found on chromosome 4A, 14 on chromosome $4 \mathrm{~B}$ and nine on chromosome 4D. For MQTL, one was reported on chromosome 4A, two on $4 \mathrm{~B}$ and two on 4D. There are two designated $L r$ genes reported on 4A, the ASR genes $L r 28$, derived from A. speltoides and Lr30 from T. aestivum (McIntosh et al. 2008). Zhang et al. (2017) reported a minor QTL in Chinese Spring (QLr.hebau-4AL) that explained 3.4 to $7.5 \%$ of the PVE.

Chromosome 4B carries the race-specific APR gene Lr12. Lr12 cosegregates with the ASR gene Lr31. However, Lr31 only confers leaf rust resistance when the complementary gene, $\operatorname{Lr} 27$ (3BS) is present (Singh et al. 1999). Previously some confusion prevailed over the arm location of $L r 12$ and $L r 31$ on chromosome 4B (Singh et al. 1999; McIntosh et al. 2008), however, subsequent studies (Singh and Bowden 2011) mapped Lr12 to the long arm of chromosome 4B, flanked by the marker loci Xgwm251 and Xgwm149.

There are 14 QTL for leaf rust resistance on chromosome 4B, with PVE ranging from 5.4\% (QLr.spa-4B) to 24.4\% (QLr.hebau$4 B$ ). QLr.spa-4B was flanked by markers $w P t-5303$ and $w P t-1849$ and is derived from cultivar Carberry. QLr.hebau- $4 B$ was reported 
in cultivar Chinese Spring linked to the markers BS00022181_51 and Excalibur_c37565_709, mapping to the same region of chromosome 4B as the race-specific APR Lr12. QLr.cim-4BS was found in cultivar Chapio and is also thought to map in the region of Lr12 (Rosewarne et al. 2015; Singh and Bowden 2011). The APR Lr49 maps to 4B and is associated with a hypersensitive response (Bansal et al. 2008; Saini et al. 2002).

Chromosome 4D possesses Lr67, an APR gene which was originally transferred from PI250143, a Pakistani wheat accession, into the Thatcher NIL RL6077 (Dyck and Samborski 1979). Lr67 is associated with the leaf-tip necrosis, Ltn3 (HerreraFoessel et al. 2014), and colocalizes with MQTL20, which is a compilation of three QTLs from PI250143, cultivar Sujata and the synthetic line TA4252-60 (Soriano and Royo 2015). In field trials Lr67 explained between 33.6 and $57.9 \%$, and 20 to $44.5 \%$ of the total PVE in cultivar Sujata and wheat line W195, respectively (Chhetri et al. 2016; Lan et al. 2015). Four other, minor effect QTL were identified on chromosome 4D: QLr.inra-4Da, QLr.B22-4D, QLr.fcu-4-DL, and QTL-4DL.

\section{CHROMOSOME GROUP 5 LINKED QTL}

Twenty QTL and two MQTL were found on the group 5 chromosomes, five QTL on 5A, 13 on 5B and three on 5D, with the two MQTL being located on 5B (Fig. 2). There are currently no designated $L r$ genes cataloged on 5A (McIntosh et al. 2008), although minor leaf rust resistance QTL have been reported. Two QTL derived from cultivar Avocet have been identified in separate studies; QLr.cim-5AC (5\% PVE; Calvo-Salazar et al. 2015) and QLr.cimmyt-5AL (5.2 to 7.4\% PVE; Rosewarne et al. 2012). Both QTL mapped close to the centromere on 5A. QLr.pbi-5AS in cultivar Beaver, QLr.sfrs-5AS in cultivar Forno, and QLr.hwwg$5 A S$ in cultivar Ning7840 are all located on the short arm, explaining 11.2, 7.7, and 7.5\% of the PVE, respectively ( $\mathrm{Li}$ et al. 2017; Messmer et al. 2000; Singh et al. 2009).

Kumar et al. (2013) found two minor APR QTL on 5B in Opata85, QLr.ccsu-5B.4 (2.5 to 8.4\% PVE) and QLr.ccsu-5B.5 (4.4 to $7.3 \%$ PVE) that were consistently observed over multiple environments and years in India. Two consistently expressed APR QTL were also found in cultivar Jamestown that explained 1.7 to $22.1 \%$ (QLr.vt-5B.1) and 3.3 to $5.5 \%$ (QLr.vt-5B.2) of the total PVE. MQTL22 and MQTL23 on 5B are comprised of the QTL mapped in Kariega and SHA3/CBRD; and Americano 25e, Capo, Carberry, and TA4152-60, respectively (Soriano and Royo 2015).

Ponce-Molina et al. (2018a) reported a significant QTL for leaf rust resistance on chromosome 5DS (QLr.cim-5DS) in wheat cultivar Chilero that accounted 5.2 to $34 \%$ of PVE. QLr.cim-5DS also colocated with a stripe rust resistance QTL ( Yr.cim-5DS). In the old Brazilian wheat cultivar Toropi, a major APR QTL, subsequently designated $\operatorname{Lr} 78$, was mapped on 5DS. $\operatorname{Lr} 78$ explained between 37 to $53 \%$ of PVE for leaf rust resistance in Toropi (Kolmer et al. 2018a).

\section{CHROMOSOME GROUP 6 LINKED QTL}

The group 6 chromosomes have the smallest number of reported leaf rust resistance QTL, with 16 QTL and five MQTL. Six QTL are found on chromosome $6 \mathrm{~A}$, seven on $6 \mathrm{~B}$ and three on $6 \mathrm{D}$. One MQTL was reported on chromosome 6A and four on 6B (Fig. 2). Two QTLs were identified in cultivar Avocet in two separate studies; QLr.cimmyt-6AL (William et al. 2006) explained from 4.2 to $6.3 \%$ and QLr.cim-6AL (Ren et al. 2017) from 8.5 to $12.6 \%$ of the total PVE. QLr.cim-6AL is colocated with the stripe rust resistance QTL, QYr.cim-6AL. Li et al. (2017) reported a minor QTL on 6AS (QLr.hwwg-6AS) in cultivar Clark, that explained between 5.0 to $7.1 \%$ of PVE.
Of the seven QTL on chromosome 6B, QLr.inra-6B, derived from cultivar Balance, explained from 3.4 to $29.2 \%$ of leaf rust resistance PVE, and cosegregated with the yellow rust resistance QTL QYr.sun-6B (Azzimonti et al. 2014).

The synthetic wheat Syn022L and the wheat line HD29 are the only hexaploid wheat genotypes where quantitative leaf rust resistance has been found on chromosome 6D. QLrs.B22-6D from Syn022L is an ASR, although only explaining 3.2\% of the PVE in seedling tests, while in field trials QLr.B22-6D confers $2 \%$ of the PVE (Naz et al. 2008).

\section{CHROMOSOME GROUP 7 LINKED QTL}

Forty-three QTL and seven MQTL have been reported on chromosomes 7 homeologs, three on 7A, 19 on 7B and 21 on 7D (Fig. 2). For MQTL, one was identified on chromosome 7A, four on 7B and two on 7D (Fig. 2). However, of the 21 QTL reported on chromosome 7D, 19 correspond to Lr34. On 7A, Azzimonti et al. (2014) identified the QTL QLr.inra-7Aa in cultivar Balance that conferred 10.0 to $69.4 \%$ of the PVE; however, this was later found to be an ASR gene and designed Lr20. A minor QTL on 7A, derived from the breeding line MN98550-5 and conferring 2.2 to $8.1 \%$ of PVE was reported by Tsilo et al. (2014).

Four of the reported 19 QTL on chromosome 7B are probably Lr68. Lr68 is a slow rusting resistance gene and is associated with a leaf tip necrosis phenotype (Herrera-Foessel et al. 2012). QLr. $h b u-7 B L$ (cultivar Fuyu 3) and QLr.hwwg-7BL (wheat line CI13227) colocate with $\operatorname{Lr68}$ and explained between 4.1 to $4.3 \%$ and 6.3 to $13.9 \%$ of PVE, respectively. QLr.sfr-7B.1 (cultivar Forno) and QLr.ksu-7BL (cultivar Opata 85) are large effect APR QTL, each explaining $35.8 \%$ and from 11.0 to $42.2 \%$ of PVE, respectively (Faris et al. 1999; Messmer et al. 2000). The MQTL33 on chromosome 7B consisted of 11 QTL that originate from wheat cultivars Colosseo, Creso, and Sujata (Soriano and Royo 2015). MQTL33 colocalizes with the ASR gens $\operatorname{Lr} 14$, Lr19 and the APR $\operatorname{Lr} 68$.

Lr34 on 7DS was reported in 19 publications, explaining from 8.0 to $75.2 \%$ of the PVE, depending on the cross and environment. Lr34 was first described in Brazilian cultivar Frontana and could be traced to Italian cultivar Mentana (Lagudah et al. 2009). In the meta-analysis of Soriano and Royo (2015) Lr34 corresponded to the MQTL34. Two minor APR QTL have also been mapped on 7D, QLr.cim-7DS in cultivar Francolin\#1 and QLr.hebau-7DS in cultivar Naxos.

\section{CONCLUSION}

Leaf rust is a major, global threat to wheat production. To date the control of leaf rust has primarily been through the use of fungicides and the deployment of major, ASR genes. However, increasing reliance on ASR is proving inadequate to achieve effective resistance throughout the commercial life of a wheat cultivar, while resulting in pathogen populations with ever increasing complex virulence profiles. With more ASR genes rapidly becoming ineffective and fewer ASR genes being found to replace them, wheat breeders are turning their attentions to quantitative sources of leaf rust resistance.

The work of CIMMYT (Singh et al. 2000) has clearly shown that effective leaf rust resistance can be achieved by combining four to five quantitative resistance QTL together. In selecting suitable resistance QTL to combine together one must know whether starting materials contain the same or different sources of resistance, how stable the expression of each resistance source is in different environments, and whether there is a positive or negative interaction between different resistance genes/QTL.

Numerous studies of field, quantitative leaf rust resistance have been published in a very wide range of wheat germplasm. 
However, these reports are rarely systematically analyzed, summarizing the genetic diversity underlying quantitative resistance in hexaploid wheat to the leaf rust pathogen $P$. triticina. In this review we summarize all published sources of quantitative leaf rust resistance, found in hexaploid wheat, that have shown to be effective under field conditions. The potential value of each leaf rust resistance QTL reported is assessed in terms of the percentage phenotypic variance explained by the QTL in the specific wheat cross, and across multiple environments and years, where tested. This review therefore provides wheat pathologists and breeders with a summary of the potential sources of quantitative leaf rust resistance available in a wide range of wheat genotypes, enabling them to select those QTL most appropriate to their requirements.

\section{LITERATURE CITED}

Azzimonti, G., Marcel, T. C., Robert, O., Paillard, C., Lannou, C., and Goyeau, H. 2014. Diversity, specificity and impacts on field epidemics of QTL involved in components of quantitative resistance in the wheat leaf rust pathosystem. Mol. Breed. 34:549-567.

Bansal, U. K., Hayden, M. J., Venkata, B. P., Khanna, R., Saini, R. G., and Bariana, H. S. 2008. Genetic mapping of adult plant leaf rust resistance genes $L r 48$ and $L r 49$ in common wheat. Theor. Appl. Genet. 117:307-312.

Basnet, B. R., Singh, R. P., Ibrahim, A. M. H., Herrera-Foessel, S. A., Huerta-Espino, J., Lan, C., and Rudd, J. C. 2014. Characterization of Yr54 and other genes associated with adult plant resistance to yellow rust and leaf rust in common wheat Quaiu 3. Mol. Breed. 33:385-399.

Broman, K. 2001. Review of statistical methods for QTL mapping in experimental crosses. Lab. Anim. 30:44-52.

Buerstmayr, M., Matiasch, L., Mascher, F., Vida, G., Ittu, M., Robert, O., Holdgate, S., Flath, K., Neumayer, A., and Buerstmayr, A. 2014. Mapping of quantitative adult plant field resistance to leaf rust and stripe rust in two European winter wheat populations reveals colocation of three QTL conferring resistance to both rust pathogen. Theor. Appl. Genet. 127: 2011-2028.

Calvo-Salazar, V., Singh, R. P., Huerta-Espino, J., Cruz-Izquierdo, S., Lobato-Ortiz, R., Sandoval-Islas, S., Vargas-Hernandez, M., German, S., Silva, P., Basnet, B. R., Lan, C. X., and Herrera-Foessel, S. A. 2015. Genetic analysis of resistance to leaf rust and yellow rust in spring wheat cultivar Kenya Kongoni. Plant Dis. 99:1153-1160.

Chester, K. S. 1943. The decisive influence of late winter weather on wheat leaf rust epiphytotics. Plant Dis. Rep. Suppl. 143:133-144.

Chhetri, M., Bansal, U., Toor, A., Lagudah, E., and Bariana, H. 2016. Genomic regions conferring resistance to rust diseases of wheat in a W195/BTSS mapping population. Euphytica 209:637-649.

Chu, C. G., Friesen, T. L., Xu, S. S., Faris, J. D., and Kolmer, J. A. 2009. Identification of novel QTLs for seedling and adult plant leaf rust resistance in a wheat doubled haploid population. Theor. Appl. Genet. 119:263-269.

Dakouri, A., McCallum, B. D., Walichnowski, A. Z., and Cloutier, S. 2010. Fine-mapping of the leaf rust Lr34 locus in Triticum aestivum (L.) and characterization of large germplasm collections support the $\mathrm{ABC}$ transporter as essential for gene function. Theor. Appl. Genet. 121:373-384.

Du, Z., Che, M., Li, G., Chen, J., Quan, W., Guo, Y., Wang, Z., Ren, J., Zhang, H., and Zhang, J. 2015. A QTL with major effect on reducing leaf rust severity on the short arm of chromosome $1 \mathrm{~A}$ of wheat detected across different genetic backgrounds and diverse environments. Theor. Appl. Genet. 128:1579-1594.

Dyck, P. L. 1977. Genetics of leaf rust reaction in three introductions of common wheat. Can. J. Genet. Cytol. 19:711-716.

Dyck, P. L. 1987. The association of a gene for leaf rust resistance with the chromosome 7D suppressor of stem rust resistance in common wheat. Genome 29:467-469.

Dyck, P. L., and Samborski, D. J. 1979. Adult plant resistance in PI250413, an introduction of common wheat. Can. J. Genet. Cytol. 59:329-332.

Elbasyoni, I. S., El-Orabey, W. E., Baenziger, P. S., and Eskridge, K. M. 2017. Association mapping for leaf and stem rust resistance using worldwide spring wheat collection. Asian J. Biol. 4:1-25.

Faris, J. D., Li, W. L., Liu, D. J., Chen, P. D., Gill, B. S. 1999. Candidate gene analysis of quantitative disease resistance in wheat. Theor. Appl. Genet. 98: 219-225

Food and Agriculture (FAO). 2015. Organization of the United Nations, Disponível em. http://www.fao.org/faostat/en/\#data/CC

Gao, L., Turner, M. K., Chao, S., Kolmer, J., and Anderson, J. A. 2016. Genome wide association of seedling and adult plant resistance in elite spring wheat breeding lines. PLoS One 11:e0148671.
Gerard, G. S., Kobiljskic, B., Lohwasserd, U., Borner, A., and Simon, M. R. 2018. Genetic architecture of adult plant resistance to leaf rust in a wheat association mapping panel. Plant Pathol. 67:584-594.

Goffinet, B., and Gerber, S. 2000. Quantitative trait loci: A meta-analysis. Genetics 155:463-473.

Griffiths, S., Sharp, R., Foote, T. N., Bertin, I., Wanous, M., Reader, S., Colas, I., and Moore, G. 2006. Molecular characterization of $P h 1$ as a major chromosome pairing locus in polyploid wheat. Nature 439:749-752.

Hackett, C. A. 2002. Statistical methods for QTL mapping in cereals. Plant Mol. Biol. 48:585-599.

Haider, D. 2013. The origin of the B-genome of bread wheat (Triticum aestivum L.). Russ. J. Genet. 49:263-274.

Helguera, M., Khan, I. A., Kolmer, J., Lijavetzky, D., Zhong-qi, L., and Dubcovsky, J. 2003. PCR assays for the Lr37-Yr17-Sr38 cluster of rust resistance genes and their use to develop isogenic hard red spring wheat lines. Crop Sci. 43:1839-1847.

Herrera-Foessel, S. A., Singh, R., Lillemo, M., Huerta-Espino, J., Bhavani, S., Singh, S., Lan, C., Calvo-Salazar, V., and Lagudah, E. S. 2014. Lr67/Yr46 confers adult plant resistance to stem rust and powdery mildew in wheat. Theor. Appl. Genet. 127:781-789.

Herrera-Foessel, S. A., Singh, R. P., Huerta-Espino, J., Rosewarne, G. M., Periyannan, S. K., Viccars, L., Calvo-Salazar, V., Lan, C. X., and Lagudah, E. S. 2012. Lr68: A new gene conferring slow rusting resistance to leaf rust in wheat. Theor. Appl. Genet. 124:1475-1486.

Hiebert, C. W., Thomas, J. B., McCallum, B. D., Humphreys, D. G., DePauw, R. M., Hayden, M. J., Mago, R., Schnippenkoetter, W., and Spielmeyer, W. 2010. An introgression on wheat chromosome 4DL in RL6077 (Thatcher*6/ PI 250413) confers adult plant resistance to stripe rust and leaf rust (Lr67). Theor. Appl. Genet. 121:1083-1091.

Huerta-Espino, J., Singh, R. P., Germán, S., McCallum, B. D., Park, R. F., Chen, W. Q., Bhardwaj, S. C., and Goyeau, H. 2011. Global status of wheat leaf rust caused by Puccinia triticina. Euphytica 179:143-160.

Jighly, A., Alagu, M., Makdis, F., Singh, M., Singh, S., Emebiri, L. C., and Ogbonnaya, F. C. 2016. Genomic regions conferring resistance to multiple fungal pathogens in synthetic hexaploid wheat. Mol. Breed. 36:127.

Kankwatsa, P., Singh, D., Thomson, P. C., Babiker, E. M., Bonman, J. M., Newcomb, M., and Park, R. F. 2017. Characterization and genome-wide association mapping of resistance to leaf rust, stem rust and stripe rust in a geographically diverse collection of spring wheat landraces. Mol. Breed. 37:113.

Kolmer, J. A. 2015. A QTL on chromosome 5BL in wheat enhances leaf rust resistance of Lr46. Mol. Breed. 35:74.

Kolmer, J. A., Bernardo, A., Bai, G., Hayden, M. J., and Chao, S. 2018a. Adult plant leaf rust resistance derived from Toropi wheat is conditioned by $\operatorname{Lr} 78$ and three minor QTL. Phytopathology 108:246-253.

Kolmer, J. A., Chao, S., Brown-Guedira, G., Bansal, U., and Bariana, H. 2018c. Adult plant leaf rust resistance derived from the soft red winter wheat cultivar 'Caldwell' maps to chromosome 3BS. Crop Sci. 58:152-158.

Kolmer, J. A., Su, Z., Bernardo, A., Bai, G., and Chao, S. 2018b. Mapping and characterization of the new adult plant leaf rust resistance gene $L r 77$ derived from Santa Fe winter wheat. Theor. Appl. Genet. 131:1553-1560.

Korte, A., and Farlow, A. 2013. The advantages and limitations of trait analysis with GWAS: A review. Plant Methods 9:29.

Krattinger, S. G., Lagudah, E. S., Spielmeyer, W., Singh, R. P., Huerta-Espino, J., McFadden, H., Bossolini, E., Selter, L. L., and Keller, B. 2009. A putative $\mathrm{ABC}$ transporter confers durable resistance to multiple fungal pathogens in wheat. Science 323:1360-1363.

Kumar, A., Chhuneja, P., Jain, S., Kaur, S., Balyan, H. S., and Gupta, P. K. 2013. Mapping main effect QTL and epistatic interactions for leaf rust and yellow rust using high density ITMI linkage map. Aust. J. Crop Sci. 7: 492-499.

Lagudah, E. 2011. Molecular genetics of race non-specific rust resistance in wheat. Euphytica 179:81-91.

Lagudah, E. S., Krattinger, S. G., Herrera-Foessel, S., Singh, R. P., Huerta-Espino, J., Spielmeyer, W., Brown-Guedira, G., Selter, L. L., and Keller, B. 2009. Gene-specific markers for the wheat gene $\operatorname{Lr} 34 / \mathrm{Yr} 18 / \mathrm{Pm} 38$ which confers resistance to multiple fungal pathogens. Theor. Appl. Genet. 119:889-898.

Lan, C., Rosewarne, G. M., Singh, R. P., Herrera-Foessel, S. A., Huerta-Espino, J., Basnet, B. R., Zhang, Y., and Yang, E. 2014. QTL characterization of resistance to leaf rust and stripe rust in the spring wheat line Francolin\#1. Mol. Breed. 34:789-803.

Lan, C., Zhang, Y., Herrera-Foessel, S. A., Basnet, B. R., Huerta-Espino, J., Lagudah, E. S., and Singh, R. P. 2015. Identification and characterization of pleiotropic and co-located resistance loci to leaf rust and stripe rust in bread wheat cultivar Sujata. Theor. Appl. Genet. 128:549-561.

Leonova, I. N., Röder, M. S., Kalininaa, N. P., and Budashkina, E. B. 2008. Genetic analysis and localization of loci controlling leaf rust resistance of 
Triticum aestivum x Triticum timopheevii introgression lines. Russ. J. Genet. 44:1431-1437.

Levine, M. N. 1919. The epidemiology of cereal rusts in general and of the black stem rust in particular. U.S. Dept. Agric. (Mimeogr.)

Li, H., Vikran, P., Singh, R. P., Kilian, A., Carling, J., Song, J., Burgueno-Fereira, J. A., Bhavani, S., Huerta-Espino, J., Payne, T., Sehgal, D., Wenzl, P., and Singh, S. 2015. A high density GBS map of bread wheat and its application for dissecting complex disease resistance traits. BMC Genomics 16:216.

Li, C., Wang, Z., Li, C., Bowden, R., Bai, G., Su, Z., and Carver, B. F. 2017. Mapping of quantitative trait loci for leaf rust resistance in the wheat population Ning7840 x Clark. Plant Dis. 101:1974-1979.

Li, Z., Lan, C., He, Z., Singh, R. P., Rosewarne, G. M., Chen, X. C., and Xia, X. 2014. Overview and application of QTL for adult plant resistance to leaf rust and powdery mildew in wheat. Crop Sci. 54:1907-1925.

Lillemo, M., Asalf, B., Singh, R. P., Huerta-Espino, J., Chen, X. M., He, Z. H., and Bjørnstad, A. 2008. The adult plant rust resistance loci $L r 34 / Y r 18$ and Lr46/Yr29 are important determinants of partial resistance to powdery mildew in bread wheat line Saar. Theor. Appl. Genet. 116:1155-1166.

Ling, H. Q. 2013. Draft genome of the wheat A-genome progenitor Triticum urartu. Nature 496:87-90.

Lowe, I., Cantu, D., and Dubcovsky, J. 2011. Durable resistance to the wheat rusts: Integrating systems biology and traditional phenotype-based research methods to guide the deployment of resistance genes. Euphytica 179:69-79.

Lynch, M., and Walsh, B. 1998. Genetics and Analysis of Quantitative Traits. Sinauer, Sunderland, MA.

McCallum, B. D., Hiebert, C. W., Cloutier, S., Bakkeren, G., Rosa, S. B., Humphreys, D. G., Marais, G. F., McCartney, C. A., Panwar, V., Rampitsch, C., Saville, B. J., and Wang, X. 2016. A review of wheat leaf rust research and the development of resistant cultivars in Canada. Can. J. Plant Pathol. $38: 1-18$

McIntosh, R. A., Wellings, C. R., and Park, R. F. 1995. Wheat Rusts. An Atlas of Resistance Genes. CSIRO Australia. Kluwer Academic Publishers, Dordrecht.

McIntosh, R. A., Yamazaki, Y., Dubcovsky, J., Rogers, J., Morris, C., Somers, D. J., Appels, R., and Devos, K. M. 2008. Catalogue of gene symbols for wheat. National BioResource Project, Komugi-Wheat Genetic Resources Database. http://shigen.nig.ac.jp/wheat/komugi/genes/download.jsp

Messmer, M. M., Seyfarth, R., Keller, M., Schachermayr, G., Winzeler, M., Zanetti, S., Feuillet, C., and Keller, B. 2000. Genetic analysis of durable leaf rust resistance in winter wheat. Theor. Appl. Genet. 100:419-431.

Moore, J. W., Herrera-Foessel, S., Lan, C., Schnippenkoetter, W., Ayliffe, M., Huerta-Espino, J., Lillemo, M., Viccars, L., Milne, R., Periyannan, S., Kong, X., Spielmeyer, W., Talbot, M., Bariana, H., Patrick, J. W., Dodds, P., Singh, R., and Lagudah, E. 2015. A recently evolved hexose transporter variant confers resistance to multiple pathogens in wheat. Nat. Genet. 47: 1494-1500.

Naz, A. A., Kunert, A., Lind, V., Pillen, K., and Léon, J. 2008. AB-QTL analysis in winter wheat: II. Genetic analysis of seedling and field resistance against leaf rust in a wheat advanced backcross population. Theor. Appl. Genet. 116:1095-1104.

Nesbitt, M., and Samuel, D. 1996. From staple crop to extinction? The archaeology and history of the hulled wheats. In: Hulled Wheats Proc. 1st International Workshop Hulled Wheats. S. Padulosi, K. Hammer, and J. Heller, eds. International Plant Genetic Resources Institute.

Ponce-Molina, L. J., Huerta-Espino, J., Singh, R. P., Basnet, B. R., Alvarado, G., Randhawa, M. S., Lan, C. X., Aguilar-Rincon, V. H., Lobato-Ortiz, R., and Garcia-Zavala, J. J. 2018a. Characterization of leaf rust and stripe rust resistance in spring wheat 'Chilero'. Plant Dis. 102:421-427.

Ponce-Molina, L. J., Huerta-Espino, J., Singh, R. P., Basnet, B. R., Lagudah, E., Aguilar-Rincón, V. H., Alvarado, G., Lobato-Ortiz, R., García-Zavala, J., and Lan, C. 2018b. Characterization of adult plant resistance to leaf rust and stripe rust in Indian wheat cultivar 'New Pusa 876'. Crop Sci. 58: 630-638.

Prins, R., Dreisigacker, S., Pretorius, Z., Van Schalkwyk, H., Wessels, E., Smit, C., Bender, C., Singh, D., and Boyd, L. A. 2016. Stem rust resistance in a geographically diverse collection of spring wheat lines collected from across Africa. Front. Plant Sci. 7:973.

Ren, Y., Singh, R. P., Basnet, B. R., Lan, C. X., Huerta-Espino, J., Lagudah, E. S., and Ponce-Molina, L. J. 2017. Identification and mapping of adult plant resistance loci to leaf rust and stripe rust in common wheat cultivar Kundan. Plant Dis. 101:456-463.

Riaz, A., Athiyannan, N., Periyannan, S. K., Afanasenko, O., Mitrofanova, O. P., Platz, G. J., Aitken, E. A. B., Snowdon, R. J., Lagudah, E. S., Hickey, L. T., and Voss-Fels, K. P. 2018. Unlocking new alleles for leaf rust resistance in the Vavilov wheat collection. Theor. Appl. Genet. 131: 127-144.
Rosewarne, G. M., Li, Z. F., Singh, R. P., Yang, E. N., Herrera-Foessel, S. A., and Huerta-Espino, J. 2015. Different QTL are associated with leaf rust resistance in wheat between China and Mexico. Mol. Breed. 35:127.

Rosewarne, G. M., Singh, R. P., Huerta-Espino, J., Herrera-Foessel, S. A., Forrest, K. L., Hayden, M. J., and Rebetzke, G. J. 2012. Analysis of leaf and stripe rust severities reveals pathotype changes and multiple minor QTL associated with resistance in an Avocet 9 Pastor wheat population. Theor. Appl. Genet. 124:1283-1294.

Rosewarne, G. M., Singh, R. P., Huerta-Espino, J., William, H. M., Bouchet, S., Cloutier, S., McFadden, H., and Lagudah, E. S. 2006. Leaf tip necrosis, molecular markers and $\beta 1$-proteasome subunits associated with the slow rusting resistance genes Lr46/Yr29. Theor. Appl. Genet. 112:500-508.

Saini, R. G., Kaur, M., Singh, B., Sharma, S., Nanda, G. S., Nayar, S. K., Gupta, A. K., and Nagarajan, S. 2002. Genes Lr48 and Lr49 for hypersensitive adult plant leaf rust resistance in wheat (Triticum aestivum L.). Euphytica 124:365-370.

Schnurbusch, T., Paillard, S., Schori, A., Messmer, M., Schachermayr, G., Winzeler, M., and Keller, M. 2004. Dissection of quantitative and durable leaf rust resistance in Swiss winter wheat reveals a major resistance QTL in the Lr34 chromosome region. Theor. Appl. Genet. 108:477-484.

Singh, D., Simmonds, J., Park, R. F., Bariana, H. S., and Snape, J. W. 2009. Inheritance and QTL mapping of leaf rust resistance in the European winter wheat cultivar 'Beaver'. Euphytica 169:253-261.

Singh, A., Knox, R. E., DePauw, R. M., Singh, A. K., Cuthbert, R. D., Campbell, H. L., Singh, D., Bhavani, S., Fetch, T., and Clarke, F. 2013. Identification and mapping in spring wheat of genetic factors controlling stem rust resistance and the study of their epistatic interactions across multiple environments. Theor. Appl. Genet. 126:1951-1964.

Singh, D., Park, R. F., and McIntosh, R. A. 1999. Genetic relationship between the adult plant resistance gene $\operatorname{Lr} 12$ and the complementary gene $\operatorname{Lr} 31$ for seedling resistance to leaf rust in common wheat. Plant Pathol. 48:567-573.

Singh, R. P., Huerta-Espino, J., and Rajaram, S. 2000. Achieving near-immunity to leaf and stripe rusts in wheat by combining slow rusting resistance genes. Acta Phytopathol. Entomol. Hung. 35:133-139.

Singh, R. P., Huerta-Espino, J., and William, H. M. 2005. Genetics and breeding for durable resistance to leaf and stripe rusts in wheat. Turk. J. Agric. For. 29:121-127.

Singh, R. P., Mujeeb-Kazi, A., and Huerta-Espino, J. 1998. Lr46: A gene conferring slow-rusting resistance to leaf rust in wheat. Phytopathology 88 : 890-894.

Singh, S., and Bowden, R. L. 2011. Molecular mapping of adult-plant racespecific leaf rust resistance gene Lr12 in bread wheat. Mol. Breed. 28: $137-142$

Singla, J., Lüthi, L., Wicker, T., Bansal, U., Krattinger, S. G., and Keller, B. 2017. Characterization of $\operatorname{Lr} 75$ : a partial, broad-spectrum leaf rust resistance gene in wheat. Theor. Appl. Genet. 130:1-12.

Soriano, J. M., and Royo, C. 2015. Dissecting the genetic architecture of leaf rust resistance in wheat by QTL meta-analysis. Phytopathology 105: 1585-1593.

Suenaga, K., Singh, R. P., Huerta-Espino, J., and Willian, H. M. 2003. Microsatellite markers for genes $\operatorname{Lr} 34 / \mathrm{Yr} 18$ and other quantitative trait loci for leaf rust and stripe rust resistance in bread wheat. Phytopathology 93: 881-890.

Tanno, K. I., and Willcox, G. 2006. How fast was wild wheat domesticated? Science 311:1886

Tsilo, T. J., Kolmer, J. A., and Anderson, J. A. 2014. Molecular mapping and improvement of leaf rust resistance in wheat breeding lines. Phytopathology 104:865-870.

Turner, M. K., Kolmer, J. A., Pumphrey, M. O., Bulli, P., Chao, S., and Anderson, J. A. 2017. Association mapping of leaf rust resistance loci in a spring wheat core collection. Theor. Appl. Genet. 130:345-361.

Wang, J., Li, Z., Shi, L., Zhu, L., Ren, Z., Li, X., Liu, D., and Shah, S. J. A. 2015. QTL mapping for adult-plant leaf rust resistance genes in Chinese wheat cultivar Weimai 8. Czech J. Genet. Plant Breed. 51:79-85.

William, H. M., Singh, R. P., Huerta-Espino, J., Palacios, G., and Suenaga, K. 2006. Characterization of genetic loci conferring adult plant resistance to leaf rust and stripe rust in spring wheat. Genome 49:977-990.

William, M., Singh, R. P., Huerta-Espino, J., Islas, S. O., and Hoisington, D. 2003. Molecular marker mapping of leaf rust resistance gene $L r 46$ and its association with stripe rust resistance gene $\mathrm{Yr} 29$ in wheat. Phytopathology 93:153-159.

Wu, X. L., and Hu, Z. L. 2012. Meta-analysis of QTL mapping experiments. Methods Mol. Biol. 871:145-171

Xu, X. Y., Bai, G. H., Carver, B. F., Shaner, G. E., Hunger, R. M. 2005. Mapping of QTL prolonging the latent period of Puccinia triticina infection in wheat. Theor. Appl. Genet. 110:244-251.

Xu, Y., Li, P., Yang, Z., Xu, C. 2017. Genetic mapping of quantitative trait loci in crops. Crop J. 5:175-184. 
Zhang, P., Hiebert, C. W., McIntosh, R. A., McCallum, B. D., Thomas, J. B., Hoxha, S., Singh, D., and Bansal, U. 2016. The relationship of leaf rust resistance gene $\mathrm{Lrl3}$ and hybrid necrosis gene $\mathrm{Ne} 2 \mathrm{~m}$ on wheat chromosome 2BS. Theor. Appl. Genet. 129:485-493.

Zhang, P., Yin, G., Zhou, Y., Qi, A., Gao, F., Xia, X., He, Z., Li, Z., and Liu, D. 2017. QTL mapping of adult-plant resistance to leaf rust in the wheat cross
Zhou 8425B/Chinese Spring using high-density SNP markers. Front. Plant Sci. 8:793.

Zhou, Y., Ren, Y., Lillemo, M., Yao, Z., Zhang, P., Xia, X., He, Z., Li, Z., and Liu, D. 2014. QTL mapping of adult-plant resistance to leaf rust in a RIL population derived from a cross of wheat cultivars Shanghai 3/Catbird and Naxos. Theor. Appl. Genet. 127:1873-1883. 